\title{
Experimental testing of PLA biodegradable thermoplastic in the frame of 3D printing FDM technology
}

\author{
Juraj Beniak ${ }^{1}$, Peter Križan ${ }^{1}$, Miloš Matúśs ${ }^{1}$, Michal Šajgalík ${ }^{2, *}$ \\ ${ }^{1}$ Faculty of Mechanical Engineering, Slovak University of Technology in Bratislava, Nám. Slobody \\ 17, 81231 Bratislava, Slovak Republic \\ ${ }^{2}$ Faculty of Mechanical Engineering, University of Zilina, Univerzitna 8215/1, 01026 Zilina, \\ Slovakia
}

\begin{abstract}
In the present time there are many different plastic materials and composite materials suitable for 3D printing by deposition of semi-melted material. The proper selection of correct material with suitable material properties is dependent on the situation how the produced 3D model should be used. If we need to take into account just the visual look of used material or also the mechanical properties as strength is important for loaded models for final use. The aim of this paper is to publish outputs of experimental testing for 3D models from selected materials with regards to mechanical properties of produced testing parts. Produced 3D models are from PLA biodegradable thermoplastic. Models are prepared on Fused Deposition Modelling (FDM) 3D printer. Testing is based on prepared full factors experiment with four factors on its two levels. Measured values are Tensile strength of PLA testing 3D models. In the same time there are gathered information regarding the $3 \mathrm{D}$ printing process and compared to measured tensile strength values for each sent of testing parts. All the measured data are statistically evaluated also by Analysis of Variance (ANOVA method).
\end{abstract}

Keywords: 3D printing, rapid prototyping, fused deposition modelling, PLA thermoplastic, fused filament fabrication

\section{Introduction}

There are many research articles and measurements focused on conventional material which are used for 3D model creation with using Rapid Prototyping technologies. Different rapid prototyping technologies using different materials in different consistence, with different conditions for processing and also with different properties of final model. The consistence of processed material can be as a powder, liquid material or solid material. The most wide-spread FDM (Fused Deposition Modelling) technology use solid material in form of wire. All this used material for FDM technology are based on plastic materials. The first used and also now most wide-spread material with professional FDM devices is ABS (Acrylonitrile butadiene styrene) material. In the present time we can also see many others

\footnotetext{
*Corresponding author: michal.sajgalik@fstroj.uniza.sk

Reviewers: Grzegorz Domek, Ladislav Écsi
} 
plastic materials as PolyCarbonate (PC), PLA (Polylactic acid) but also many composite materials as Laywood what is composite of polymer and wood particles. All of this materials have some advantages and disadvantages. They have different processing requirements as for example required temperature but also very important material properties as tensile strength, flexural strength or strength in compression. Selection of material for produced model depends mostly from available device type. Because not all FDM devices are able to process all available materials. The other reason how to choose the model material, when the device can process more types of materials is the final use of produced model and the material properties.

As we can see in Table 1, there is really big difference between of some material types. Some of materials have high tensile strength, others have high elongation ratio or high deformation temperature.

Table 1. Material properties used for FDM technology

\begin{tabular}{|l|l|l|l|l|l|l|}
\hline Material & $\begin{array}{l}\text { ABS } \\
\text { plus }\end{array}$ & $\begin{array}{l}\text { PC- } \\
\text { ABS }\end{array}$ & $\begin{array}{l}\text { PC- } \\
\text { ISO }\end{array}$ & PC & $\begin{array}{l}\text { Nylon } \\
\mathbf{1 2}\end{array}$ & PLA \\
\hline Tensile strength (MPa) & 37 & 41 & 57 & 68 & 48 & 65 \\
\hline Elongation (\%) & 3 & 6 & 4,3 & 4,8 & 30 & 6 \\
\hline Flexural Strength (MPa) & 53 & 68 & 90 & 104 & 69 & 80 \\
\hline Deformation temperature $\left({ }^{\circ} \mathrm{C}\right)$ & 96 & 110 & 133 & 138 & 82 & 65 \\
\hline
\end{tabular}

So in case when we need the final 3D model just for design presentation, we can use any of usable material. The only decision criterion is processing difficulties. But when we need the model as a part for final use, we have to care also about material properties, especially when the part will be loaded with some force or pressure. Because of this, we have to know what are the material properties of produced model. These properties are different from properties produced by conventional technologies, for example by plastic extrusion or injection moulding. The reason why these material properties are different is the way of part producing.

\section{Fused deposition modelling process}

The main principle is based on semi-melting of plastic material in heated nozzle and the semi-melted material is deposited fibre next to fibre in horizontal plane as one layer and then the same way layer on layer (Fig. 1). So whole model is divided to final number of layers and is built from bottom to the top.

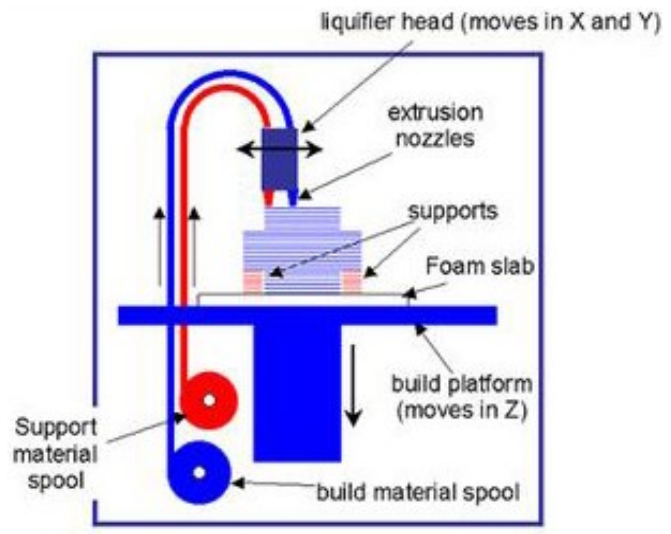

Fig. 1. Scheme of Fused Development Modeling process [1] 


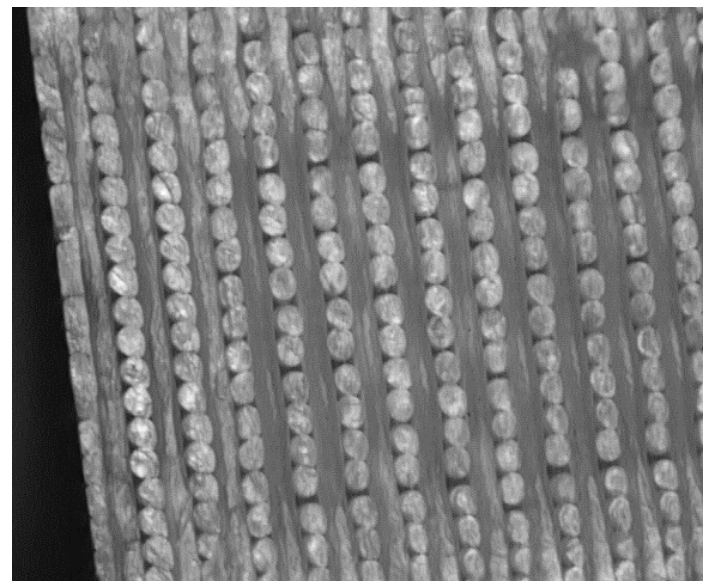

Fig. 2. Microscopic view on cross-section of built 3D model

With reference to this production process, the volume of produced part is not homogenous and is not for $100 \%$ filled in with material. As we can see on Fig. 2, the volume is created with fibre mesh. Also if we set the maximum filling of model, it is not the same as model produced by conventional technology. The material properties mentioned in Tab. 1 are for materials produced by conventional technology.

If we need to know the real properties of FDM part, we have to make experiments focused on measurements of required parameters. There are already few research articles which provides such information mostly about ABS plastic [2]. But there are no available information about PLA plastic and parts produced on small FDM 3D printers.

PLA plastic material is lately really preferred in FDM technology for their easy application and lower demands in processing. This material is not so predisposed to deformation by influence of cooling process as ABS plastic. There is also not necessary to use heating chamber and heating building platform. The advantage of PLA plastic is also its environmental friendliness. This material is natural polymer, produced from corn, potatoes or sugar-beet. This natural material transmit the light but is not transparent. Its mechanical properties are lower as in case of ABS material. For example the elasticity is worse, has lower melting temperature, what can be also disadvantage because the model can be deformed at lower temperature. The final models have better design look.

\section{Measurement of tensile strength of PLA models}

Before we start with own measurements, we had to prepare the plan of experiment or design of experiment (DOE). Because we want to know how is the tensile strength affected by different parameters, first of all we chose four important parameters. The chosen parameters are important from the point of device settings, what could affect the final tensile strength. The list of chosen factors is mentioned in Table 2.

Table 2. Selected factors and their levels

\begin{tabular}{|l|l|l|}
\hline Factor & Level 1 & Level 2 \\
\hline A - Model filling (\%) & 90 & 50 \\
\hline B - Filling shape & Perimeter lines & Honeycomb \\
\hline C - Layer thickness (mm) & 0,125 & 0,25 \\
\hline D - Model orientation & 0 deg & $45 \mathrm{deg}$ \\
\hline
\end{tabular}


Depending on selected factors and their levels we prepared full factors experiment (complete experiment plan). This plan consists from all possible combinations of all factor levels. It is the simplest and the most comprehensive plan of experiment. Allows to estimate all parameters of regression model and easy find out influence and weight of most important factors and their interactions to measured parameters [3]. If we have in our case $k$ $=4$ factors and measurement will be realized on $h=2$ levels and with accepted $q=3$ repetitions, the total number of measurement will be $N_{\mathrm{c}}=q \cdot h^{\mathrm{k}}=3 \cdot 2^{4}=48$ repetitions. The design of experiment is shown in Table 3.

Table 3. Design of full factor experiment

\begin{tabular}{|c|c|c|c|c|}
\hline exp. & $\begin{array}{c}\mathbf{A} \\
\left(\boldsymbol{x}_{\mathbf{1}}\right)\end{array}$ & $\begin{array}{c}\mathbf{B} \\
\left(\boldsymbol{x}_{\mathbf{2}}\right)\end{array}$ & $\begin{array}{c}\mathbf{C} \\
\left(\boldsymbol{x}_{\mathbf{3}}\right)\end{array}$ & $\begin{array}{c}\mathbf{D} \\
\left(\boldsymbol{x}_{\mathbf{4}}\right)\end{array}$ \\
\hline 1 & 1 & 1 & 1 & 1 \\
\hline 2 & 2 & 1 & 1 & 1 \\
\hline 3 & 1 & 2 & 1 & 1 \\
\hline 4 & 2 & 2 & 1 & 1 \\
\hline 5 & 1 & 1 & 2 & 1 \\
\hline 6 & 2 & 1 & 2 & 1 \\
\hline 7 & 1 & 2 & 2 & 1 \\
\hline 8 & 2 & 2 & 2 & 1 \\
\hline 9 & 1 & 1 & 1 & 2 \\
\hline 10 & 2 & 1 & 1 & 2 \\
\hline 11 & 1 & 2 & 1 & 2 \\
\hline 12 & 2 & 2 & 1 & 2 \\
\hline 13 & 1 & 1 & 2 & 2 \\
\hline 14 & 2 & 1 & 2 & 2 \\
\hline 15 & 1 & 2 & 2 & 2 \\
\hline 16 & 2 & 2 & 2 & 2 \\
\hline
\end{tabular}

The measured values of tensile strength are presented in Fig. 3. The measurement was realized on universal tensile machine Inspekt Desk $5 \mathrm{kN}$. The testing specimen and the experiment process was prepared and realized by ISO 527-1. Each experiment, each combination, presented in Tab. 3 was repeated 5 times, to ensure the possibility of statistical evaluation and maximize the precision of reached values. On Fig. 3 are visible the average values for each experiment [5]. 


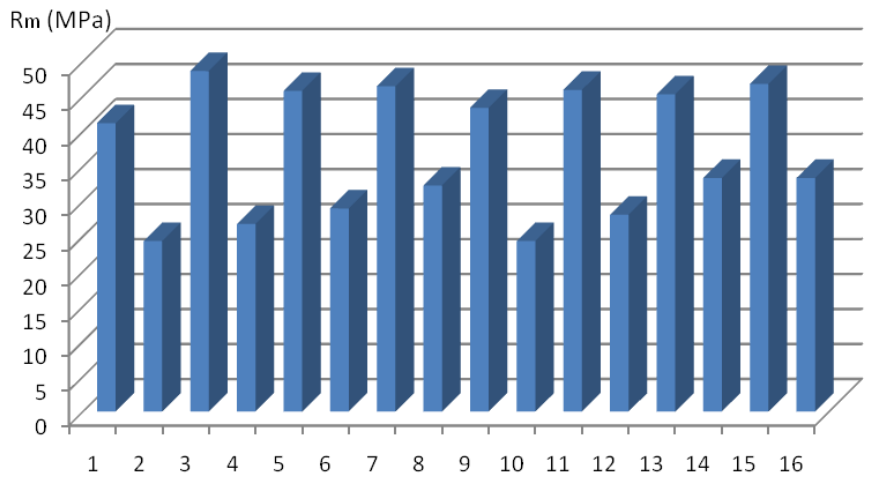

Fig. 3. Graphical illustration of measured tensile strength of PLA samples

The measured data have been evaluated by modern statistical methods. We used the ANOVA method as the base and for verification we used Students criterion and linear regression model. For processing of measured data we can use also regression analysis. This is suitable for exact specification of coefficients, which presents the weight of investigated factors. For this we selected empirical model of experiment:

$$
\boldsymbol{y}=\varphi(x, \boldsymbol{\beta})+\boldsymbol{s}
$$

Where $\boldsymbol{x}$ is vector of selected factors, $\boldsymbol{\beta}$ is vector of unknown parameters and $\boldsymbol{s}$ is vector of errors. Its parameters are estimated from empirical data by regression analysis methods. The model (1) can be replaced by power law series [4]:

$$
y=\beta_{0}+\sum_{i=1}^{k} \beta_{i} x_{i}+\sum \sum \beta_{i j} x_{i} x_{j}+\ldots+\beta_{12 \ldots k} x_{1} x_{2} \ldots x_{k}
$$

where $\beta i$ parameter is estimated from empirical data and where $\beta_{12}$ to $\beta_{12} \ldots k$ present correspondent interactions between two to $k$ factors. For simplicity we take linear regression:

$$
\begin{aligned}
R_{m}= & b_{0}+b_{1} x_{1}+b_{2} x_{2}+b_{3} x_{3}+b_{4} x_{4}+b_{1,2} x_{1} x_{2}+b_{1,3} x_{1} x_{3}+b_{1,4} x_{1} x_{4}+b_{2,3} x_{2} x_{3}+b_{2,4} x_{2} \\
& x_{4}+b_{3,4} x_{3} x_{4}+b_{1,2,3} x_{1} x_{2} x_{3}+b_{1,2,4} x_{1} x_{2} x_{4}+b_{2,3,4} x_{2} x_{3} x_{4}+b_{1,2,3,4} x_{1} x_{2} x_{3} x_{4}
\end{aligned}
$$

In formula (3) are $b_{0}, b_{1}, b_{2}, b_{3} \ldots$, point estimation $\beta_{0}, \beta_{1}, \beta_{2}, \beta_{3}, \ldots$.

Verification of each coefficient is made independently. For this verification can be used Student criterion. When using the full factors experiment or repeated measurements, the determining intervals are the same for all coefficients.

\section{Conclusions}

When we see the measured values in graphical form (Fig. 3), we can notice some regularity. Every unpaired values $(1 \mathrm{st}, 3 \mathrm{th}, \ldots)$ is much higher than the paired values $(2 \mathrm{nd}$, $\left.4^{\text {th }}, \ldots\right)$. If we compare this measured values with plan of experiment (Tab. 3 ) we realize that this significant change is caused by factor A, what is quantity of produced model filing. This is logical if we realize that higher filling means more plastic fibres in the cross-section. This statement is visible in Fig. 4. where the factor A have the biggest gap between level 1 and level 2. So the factor A is the most significant factor from all of mentioned factors. The others two significant factors are also factor $\mathrm{C}$ and factor $\mathrm{B}$, represented by layer thickness 
and filling shape. They are not so valuable as factor A but we can still see the noticeable difference.
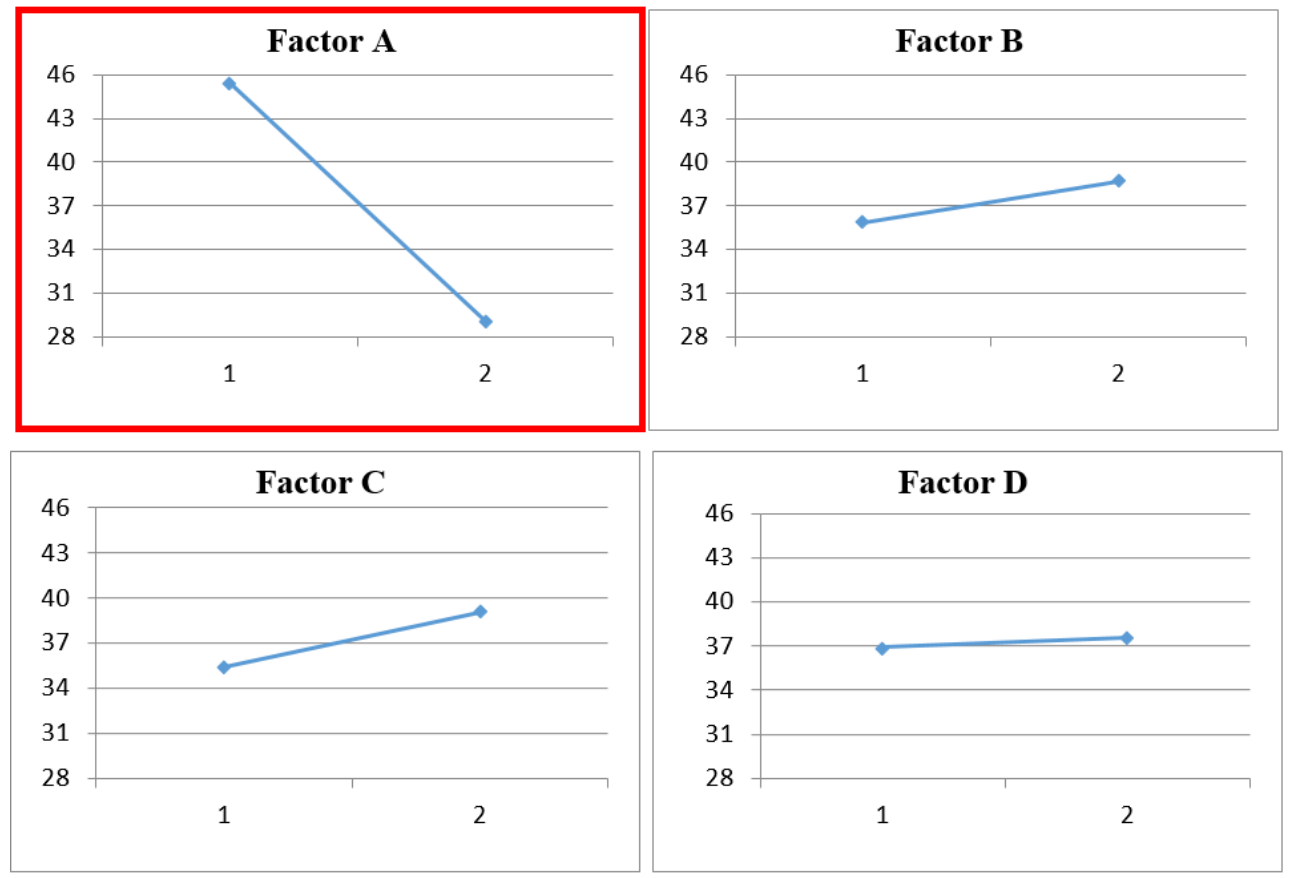

Fig. 4. Significancy overview of individual factors in monitored levels

Only the factor D is not significant, what was confirmed also with ANOVA statistical method. From the measured values we can also recognize the maximum value which have been reached in experiment number 3 . The maximum value is $48,63 \mathrm{MPa}$. This value is $75,8 \%$ from value mentioned in Tab. $1(65 \mathrm{MPa})$. This is real confirmation of our expectation stated previously.

The research presented in this paper is an outcome of the project No. APVV-0857-12 "Tools durability research of progressive compacting machine design and development of adaptive control for compaction process" funded by the Slovak Research and Development Agency.

\section{References}

1. A. Husseini, $3 D$ printing and the construction industry; technical placement. NBS, $\mathrm{http}: / / \mathrm{www}$.thenbs.com/topics/constructionproducts/articles/3d-printing-and-theconstruction-industry.asp\#figure-2 [online] (2014)

2. J. Lipina, P. Kopec, V. Krys, Implementation of Polycarbonate Material Mechanical Properties of Rapid Prototyping into System Creo, Laboratory Verification of the Results. INES 2014, IEEE 18th International Conference on Intelligent Engineering Systems, Tihany, Hungary, ISBN 978-1-4799-4615-0 (2014)

3. E. Jarošová, Navrhováni experimentů. (Česká společnost pro jakost, 1997)

4. R. Grofík, J. Kubíček, J. Hrubý, J. Dufek, B. Kába, R. Zeipelt, Štatistika. (Edícia Ekonomika pol'nohospodárstva, Príroda, 1987) 
5. J. Beniak, The factors affecting the production process of models by FDM device. Habilitation thesis, Slovak University of Technology, ISBN 978-80-227-4300-6 (2014) 